\title{
An Analysis of Pride and Prejudice from Structuralist Perspective
}

\author{
Jinhua Zhang ${ }^{1}$ \\ ${ }^{1}$ School of Foreign Languages, Xi' an Aeronautical University, Xi'an, China \\ Correspondence: Jinhua Zhang, School of Foreign Languages, Xi'an Aeronautical University, Xi'an, China. \\ E-mail: zjhclara@163.com
}

Received: December 30, 2019 Accepted: February 13, 2020 Online Published: February 28, 2020

doi:10.5539/ells.v10n1p86

URL: https://doi.org/10.5539/ells.v10n1p86

\begin{abstract}
Pride and Prejudice is a classic novel from Jane Austen, a prominent female British writer, which has attracted considerable attention from the perspective of language, content, feminism, and marriage view but without the plot organization. Different from the previous study, this paper aims at the plot organization of the novel to see its structure and the deep meaning.

This paper is devoted to analyzing the novel from the surface and deep structure, in which the structuralist approach is employed. The surface and deep structure theory is the main clue; besides, the structuralist narratological methods are applied to analyze the cases in the novel and explore the surface structure and deep structure respectively. The concepts of surface and deep structure and the structuralist narratological methods were applied to analyze Pride and Prejudice to see how the plots act to serve for the theme.

The paper shows that the achievement of a novel is closely related to its complement of the structure. The clear hierarchies can effectively elaborate the story and the theme. To divide the plot into several parts can easily control and handle the development and interaction of the plots. The relative and oppositional relations of the different plots contribute to the demonstration of the theme and the comprehension of the readers.
\end{abstract}

Keywords: Pride and Prejudice, structuralism, plot organization, deep structure and surface structure, structuralist narratological methods

\section{Introduction}

In the $18^{\text {th }}-19^{\text {th }}$ century, England is an orthodox patriarchal society in which marriage is the best way and even the only way for women to gain some social status and recognition. Under such a social reality, Jane Austen looked forward to the true love with the freedom. She expected that women can pursue their own love freely and bravely, so she created the figure Elizabeth Bennet. This novel has attracted considerable attention because of its sensitive topic and theme. Many scholars studied it from both content and form, especially from the feminist perspective. Since the status of the women is a global issue, Austen's efforts and new marriage view reflected in the novel attract the global attention.

Structuralism was proposed by Ferdinand de Saussure and it was emerging as a linguistics theory applied more often in linguistics. Its theory, approach, and achievements had much controversy in the west in last century. In recent years, an increasing number of literary critics employ structuralist approaches in literature analysis. The application of linguistic theories in literature has been regarded as a very active and useful way to analyze literary works. Many people use linguistic theories to study the discourse in the text of work, but people who explore the theme and organization of the work in linguistic theories are rare.

Thus, this paper combines Pride and Prejudice with the structuralism to analyze this novel's plots organization. This study will give readers a new sight and set a good example in text organization for the following writers. The paper has both theoretical and practical significance.

The paper tries to answer the following questions: 1) what is the theme of the novel? 2) How is the plot designed and how does it work for the novel? 3) How does the sub-plots relate to each other to serve for the theme or the main line?

\section{Previous Studies About Pride and Prejudice}

Scholars at home and abroad have carried out a lot of research on this novel. In the background of that period of time, it is distinctive because of its unique feminist characters, which attracts much attention from a large 
number of scholars. They have done the research from different perspectives, including studies from the content, the language, the feminism, the marriage view, pragmatics and other aspects.

Huang (2011) and Zhang (2011) have studied this novel from feminism. Tang (2006) started the analysis from the figures in the novel and studies the consciousness of women from the literary criticism view. $\mathrm{Li}$ and $\mathrm{Li}$ (2010) and $\mathrm{Hu}$ (2012) studied the marriage view reflected in the novel. Geng (2011) studies the four marriages in the novel and gets a conclusion that every person's character reflects their different attitudes towards the marriage. Zhao (2010) analyzes a certain conversation extracted from Pride and Prejudice, sticking to show Jane Austen's writing style and writing techniques and to propose that pragmatic theories should be combined together to explain a certain linguistic phenomenon in literature works perfectly. Some other scholars study this novel from other perspectives. Zeng (2012) studied the novel from the tension theory perspective.

The studies so far are mainly about the language, content, feminism, marriage view, and the theories employed are mainly feminism, pragmatics, appraisal theory and tension theory, but few people have studied this novel from the perspective of text organization.

\section{Research Questions and Theory}

\subsection{Research Questions}

The research subject is the analysis of Pride and Prejudice, which aims at studying the organization of the novel and its deep meaning behind the surface structure in plots. Through this research, readers will have an overall impression on the whole novel from the bird-eye view. It is easier for them to understand and grasp the structure of the novel.

The paper is aimed at studying how the plots are designed and how it works for the novel. In order to explain the research subject and achieve this goal, the research is developed to solve some questions.

(1) How does the plot work for the novel?

(2) How is the theory applied to the study?

(3) How do the sub-plots relate to each other to serve for the theme or the main line?

(4) What is the deep meaning behind the surface structure?

\subsection{Research Theory}

This paper aims at studying the organization of the novel, which will analyze the novel from surface structure to deep structure. Structuralism is the main theory of the research, in which the core concept of surface and deep structure is employed. And then two structuralist narratological methods are applied in the case analysis to search the surface and deep structure respectively.

In the process of the analysis, Greimas' semiotic rectangle and Greimas' actants model are applied in the case analysis. Greimas' semiotic rectangle theory is a formalist narrative analysis theory, which searches the basic structure of the meaning. Greimas' semiotic rectangle theory is more abstract than actants model theory.

In structuralists' view, characters are the result of the plots and the action is of the great importance. Greimas raises that there are six actants in the main story, namely sender and the receiver, helper and opponent, and the subject and object. These three contrary relations describe three possible modes happening in the narration: desire, pursuit or goal; communication; additional support or obstruction. Analyzing the story with Greimas' actants model theory, we can find the basic narrative structure and the surface meaning in the story. Thus Greimas' actants model theory is a reliable method to analyze the surface structure of the novel.

In the analysis, the first step is to find subject \& object. Greimas thinks that subject must have desire and if the subject wants desire to be achieved, subject must pursue it seriously. In this pair of relationship, if A wants to pursue B, then A is subject and B is object. The second step is to find the sender and the receiver. Usually, subject and receiver are in one side and object and the sender are in another side. The third step is to find the helper and opponent of the text. This pair of actants promote the development of the plot in the novel. They can help subject to achieve the desire and contribute to the communication. On the other hand, it sometimes makes some obstructions for the desire. This pair of the actants help the novel be more complicated and also enrich the meaning of the novel. This forms the actants model and it can be represented by a picture as follows: 


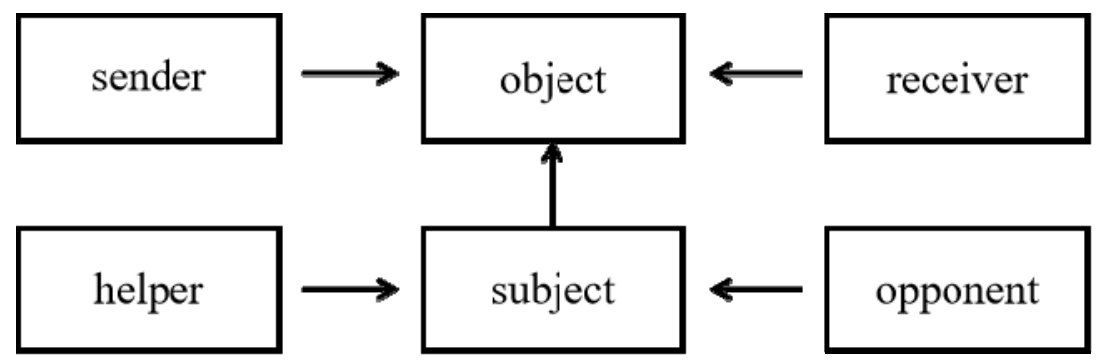

Figure 1. Greimas' actants model

With his research, Greimas is influenced by the binary opposition theory in linguistics. He holds the idea that all the meaning is generated from the opposition of the semantic elements. Such an opposition is divided into two groups: entity and the opposition of the entity, entity and the negative of the entity. He broadens his theory on this basis and proposes the rectangle mode.

The paper analyzes the binary opposition relationship in the main plots and explains the meaning behind them. In this theory, Greimas notes that binary opposition is the basic rule that generates the meaning and basic aspect in the deep structure of the narration works. In the text of the novel, it is supposed that the protagonist is S1 then there must be an opposite character S2. That is to say, S1 and S2 are a pair of binary opposition. And usually, there are helpers which can be represented by S1-, and there are non-helpers which are the helpers of S2. We can use S2- to represent them. This kind of relationship can be drawn as a picture as follows:

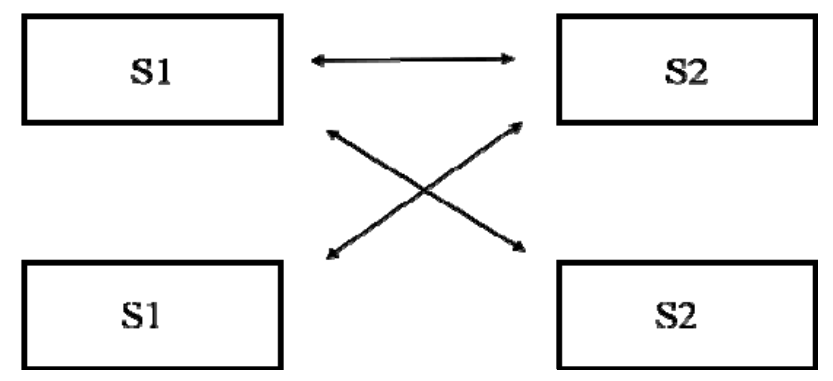

Figure 2. Greimas' semiotic rectangle

\subsection{Case Collection}

In the novel, there are mainly five couples, namely Mr. Bennet \& Mrs. Bennet, Jane \& Bingley, Elizabeth \& Darcy, Collins \& Charlotte and Wickham \& Lydia. These five couples interact with each other and the relationship among them is complicated. In these five couples, marriage between Darcy and Elizabeth is the main line of the content.

A lot of supports and obstructions are designed in their emotion development, so it is significant enough to be regarded as a line to study their development of the emotion. What happened in this line will be the case that the paper is devoted to studying. For instance, (1) what happened in the ball at the beginning of the novel; In this plot, Darcy looks down upon Elizabeth and Elizabeth has a bad impression on Darcy. (2) With time going on, Darcy has changed his mind but Wickham says some ill words on Darcy, which deepens Elizabeth's misunderstanding. (3) Darcy gives money to Wickham to promote Lydia and Wickham's marriage thus saves the reputation of Elizabeth's family. (4) Lady Catherine's obstruction to their marriage; (5) Elizabeth gets married to Darcy.

\section{Case Analysis and Discussion}

Two narratological methods aim at different hierarchies. Greimas' actants model theory is applied to study the surface structure, and Greimas' semiotic rectangle theory is applied to research the deep meaning of the novel. The whole analysis is from surface structure to deep structure with highly hierarchal progressive layers.

\subsection{The Application of Greimas' Actants Model Theory}

Elizabeth and Darcy's marriage are the main line of the novel. Among five couples, Elizabeth and Darcy are the 
couple who insist their true love. However, it is not smooth for subject to pursue the object, in which opponent will obstruct the subject while helper will provide support for subject. With the development of the event, the helper and the opponent may change.

In this part, Greimas' actants model is applied in the novel to analyze its surface structure. This theory is composed of six actants and they can be classified into three pairs of binary oppositions: subject and object, sender and receiver, helper and opponent, which can be listed as follows:

Subject: Darcy and Elizabeth

Object: marriage

Sender: Darcy and Elizabeth's brave pursuit to true love

Receiver: Darcy and Elizabeth

Helper: difficulties they meet in the process of they know each other

Opponent: the gap in the status

\subsubsection{Subject and Object}

In Pride and Prejudice, the subject is Darcy and Elizabeth, and the object is the marriage. The object is clarified clearly at the beginning of the novel. The initial sentence in the novel presents that "It is a truth universally acknowledged that a single man in possession of a good fortune must be in want of a wife", in which the topic of the novel, marriage, is presented. As stated in the novel, Darcy is a rich bachelor, so he must have the desire to get married. As for Elizabeth, her mother grasps all kinds of opportunities to find husband for her daughters and Jane falls in love with Bingley in the ball quickly, so Elizabeth's marriage is the priority in her whole family. That is to say, both Darcy and Elizabeth have desires to get marriage. Therefore, we can judge that subject is Darcy and Elizabeth and object are the marriage. The conflicts and interactions between subject and object form the basic framework of the novel.

\subsubsection{Sender and Receiver}

The sender in the story is the brave pursuit to true love from Darcy and Elizabeth, which drives the development of their emotion. For instance, facing the obstruction, Elizabeth fights against Lady Catherine:

"Neither duty, nor honor, nor gratitude," replied Elizabeth, "have any possible claim on me, in the present instance. No principle of either would be violated by my marriage with Mr. Darcy. And with regard to the resentment of his family, or the indignation of the world, if the former were excited by his marrying me, it would not give me one moment's concern - and the world in general would have too much sense to join in the scorn." (Austen, 2010, p. 353)

If they do not pursue the love bravely, their true love can not be achieved. Finally, Darcy and Elizabeth get married. The final receiver is Darcy and Elizabeth because the story aims at advocating the true love between Darcy and Elizabeth and their brave pursuit to true love.

\subsubsection{Helper and Opponent}

Various helpers and opponents appear in the development of the emotion between Darcy and Elizabeth. Some of them change under different circumstances.

Since Darcy and Elizabeth meet each other in the ball, they leave bad impression on each other. Darcy is a rich gentleman with a high social status, so he can not bear some behaviors from Mrs. Bennet, thus in his mind all her families are in low status and behave badly. Accordingly, he looks down upon Elizabeth. In the ball, he does not dance with anyone, which demonstrates his pride and also irritates Elizabeth. From then on, Elizabeth has much prejudice to Darcy. Here, we can see that a big opponent is the large status gap between them, which is also the main opponent in the whole story.

However, there are some other variable actants. With the time going on, their roles change under the different circumstances.

At the beginning, Wickham is a big opponent in the development of their emotion. Wickham says many ill words about Darcy in front of Elizabeth.

"A thorough, determined dislike of me - a dislike which I cannot but attribute in some measure to jealousy. Had the late Mr. Darcy liked me less, his son might have borne with me better; but his father's uncommon attachment to me, irritated him I believe very early in life. He had not a temper to bear the sort of competition in which we stood - the sort of preference which was often given me." (Austen, 2010, p. 79) 
At that time, Elizabeth has prejudice to Darcy so Wickham's words deepen her misunderstanding to him. Under that circumstance, Wickham is an opponent in this structure. However, when the truth is revealed, Wickham's behavior highlights Darcy's loftiness, especially when Darcy gives Wickham money to help Elizabeth's sister rather than prosecuting his slander. At that time, Elizabeth is really moved by him, so we can assert that Wickham promotes their emotion. From this perspective, Wickham, to some extent, can be seen as a helper.

Similarly, lady Catherine also plays a double role in the novel. Actually, lady Catherine is the typical figure with the traditional marriage view in the story. She disagrees with the marriage between Darcy and Elizabeth because of their large status gap, which means she is a big opponent.

"The upstart pretensions of a young woman without family, connections, or fortune. Is this to be endured! But it must not, shall not be. If you were sensible of your own good, you would not wish to quit the sphere in which you have been brought up." (Austen, 2010, p. 351)

Facing the obstruction, Elizabeth fights against her. And exactly because of her opposition, Darcy knows Elizabeth's thought about his proposal. Then he proposed again and gets married to her successfully. In fact, lady Catherine becomes a helper in the end.

Another important question is how to explain what roles Mr. Bennet and Mrs. Bennet play in the whole story. In the novel, Mr. Bennet and Mrs. Bennet provide information and clues of gentlemen for their daughters. If Mrs. Bennet and Mr. Bennet are not so active for their daughters' marriages, their daughters may not participate in the ball and may not have access to get on with these gentlemen. In other words, this couple is the key role in the beginning of the story. They make the whole story possible, from which they are also the helpers in this actants model.

Similarly, Jane and Bingley are also the helpers in this story. At the beginning, Jane and Bingley fall in love with each other but they suffer a lot of obstructions including that from Darcy. After knowing that, Elizabeth talks with Darcy, who persuades Darcy what kind of a person Jane is. He admits his fault immediately and then corrects his fault soon, through which Elizabeth believes him finally. Here, we can see that the emotion between Jane and Bingley is a promoter to the emotion between Elizabeth and Darcy.

The whole story starts from the arrival of Bingley and Darcy, and the narration of the story is developed by the chronological order. In the development of the story, it can be divided into three parts: the generation of the desire, the communication and the support or obstruction. We can see that these parts do not develop independently but interact in the text and work for each other.

\subsection{The Analysis from Greimas' Semiotic Rectangle Theory}

In this part, the Greimas' semiotic rectangle theory is employed in the plot to analyze the organization and the deep meaning of the novel.

According to Greimas' semiotic rectangle theory, the key is to find the semiotic elements and to construct the semiotic rectangle. Actually, it is hard to decide what S1 is. Here the marriage between Darcy and Elizabeth is the main plot in the whole novel and any other plot is developed to serve for it. The author struggles to make them together, which intends to express her own thoughts through this couple's fight for their love. Thus, their marriage plays the crucial role in the novel. Therefore, the marriage between Darcy and Elizabeth can be regarded as the first element $\mathrm{S} 1$.

Under the background of the society in those days, it is easy to interpret the deep meaning behind the marriage between Darcy and Elizabeth. Their social status has a big gap, but they ignore this difference and ignore the views from others to pursue their love bravely. Thus, it represents the true love which breaks the convention. On the contrary, a power of traditional marriage view obstructs them. In the novel, Miss Bingley and lady Catherine are the conservative guardian of the traditional marriage view. They have strong status views so they don't think Elizabeth has right to get married to Darcy, thus they obstruct their emotion. And in the development of their emotion, traditional status view obstructs their emotion largely.

Thus, Miss Bingley and lady Catherine can represent holders of the traditional status view, which are opposite to Darcy and Elizabeth's view. It can be S2 in the theory.

Mr. Bennet and Mrs. Bennet hold the desire that their daughters have a happy marriage, especially Mrs. Bennet. She ignores the gap in social status and on the contrary she expects her daughters can get married to rich men. Mr. Bennet is an enlightened father who respects daughters' choice and just wants to ensure they are happy. Thus, this couple manages to create conditions for their daughters to have a good marriage. And when they know Darcy proposed to Elizabeth, they are thrilled about that, so is couple Jane and Bingley. Both Jane and Bingley 
are conservative people with comparatively traditional views. Although they truly love each other, they dare not to be together without any hesitation. However, they do not agree with the traditional marriage view and status view, and they have the motivation and the ambition to break the traditional ones, so we can call them non-tradition. Therefore, they can be S1-in the semiotic rectangle. They are supporters of the true love.

In this novel, there is no concrete element to act as S2-. S2- plays the similar role with S2, so S2 and S2- are the alliance. Here, it represents the traditional resistant power. We can see that although most of people hold the traditional marriage view and status view, they have to admit the true love. Although in conventional views Darcy and Elizabeth do not match in many aspects, no one can deny true love. Thus, that is why there is no non-true love in this rectangle, which presents author's respect to true love. She believes that no matter how terrible the society is, people must admire true love, which is also the author's desire.

Now, we can get the semiotic rectangle about the surface structure:

True love

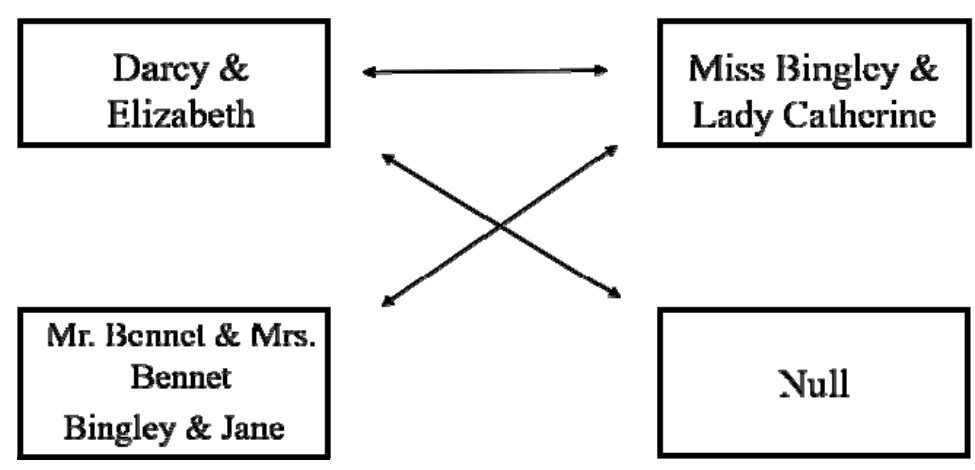

Figure 3. Semiotic rectangle of the surface structure

Non-traditional marriage view

Finally, we can get the deep structure semiotic rectangle:

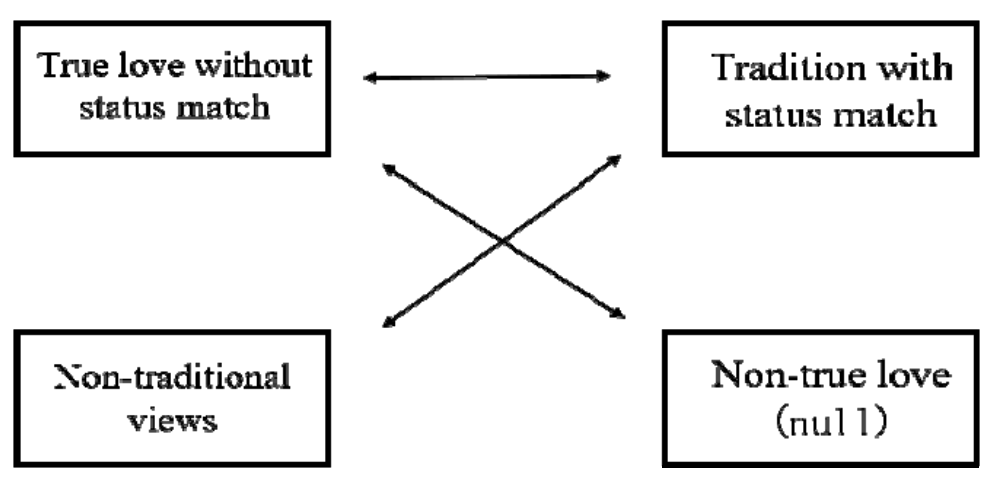

Figure 4. Semiotic rectangle of the deep structure

\section{Conclusion}

\subsection{Main Findings}

The surface structure and the deep structure of this novel are revealed in the analysis. Firstly, in the surface structure, the relationships among five main marriages are demonstrated clearly. Darcy and Elizabeth are the main roles in the novel and their emotion development goes through the whole novel. And other couples are assistants in their emotion development. In this study, we can see why the author designs these five couples. Each couple plays their distinctive role in the novel. And with the time going on, each couple and each character may change their place to play different roles. 
Secondly, in the deep structure, the deep meaning behind each character can be presented, so is each couple and even plot. Through the approach of the semiotic rectangle, readers can generalize an overall meaning behind the different elements. For instance, the marriage between Darcy and Elizabeth stands for the true love and brave pursuit even against all the traditional views. The marriage between Bingley and Jane stands for the true love under the traditional pressure because they dare not to pursue it freely and they just wait for the arrangement of the destiny. The marriage between Collins and Charlotte stands for the traditional marriage in which there is just material but no true love. The marriage between Lydia and Wickham stands for another kind of traditional marriage in which there is just their own interests but no true love. Lady Catherine stands for the rigid tradition and in her eyes, it is impossible to get together without matched status. The semiotic rectangle demonstrates us the conflicts between the traditional marriage view and Darcy and Elizabeth's desire to marriage.

\subsection{Implications of the Study}

In this analysis, it should be noted that structuralism can assist us to grasp the core meaning and logic in the literary works. We can conduct it from the analysis of the surface structure and then deepen it into the deep structure. In this way, readers can have a clear control to the whole novel. It can help readers to grasp the organization of the novel quickly. And it is much easier for readers to understand the novel. In the teaching of the literary works, this approach can simplify the text and boost students' comprehension to the work.

\section{References}

Austen, J. (2010). Pride and Prejudice. Yanbian: People Press. https://doi.org/10.1097/ACM.0b013e3181d2ed38

Geng, S. (2011). The four different marriages in Pride and Prejudice. Movie Literature, 12, 5-6. https://doi.org/10.3969/j.issn.0495-5692.2011.12.029

$\mathrm{Hu}, \mathrm{Y}$. (2012). The imperfect marriage in Pride and Prejudice. Intelligence, 4, 203-204.

Huang, T. (2011). Analysis of Jane Austen's Pride and Prejudice from the Feminist Perspective. Journal of Weinan Teachers University, 26(1), 55-57. https://doi.org/10.3969/j.issn.1009-5128.2011.01.014

Li, K., \& Li, L. (2010). The marriage between Bingley and Jane in Pride and Prejudice. Journal of Nanchang Education School, 25(4), 24-25. https://doi.org/10.3969/j.issn.1008-6757.2010.04.015

Tang, G. (2006). The Consciousness of Women in Pride and Prejudice. Unpublished master's thesis, Tianjin Normal University.

Zeng, Y. (2012). Analysis of Pride and Prejudice from the tension theory perspective. Overseas English, 2012, 228-230.

Zhang, L. (2011). Analysis of Western Marriage View in Pride and Prejudice from Feminist Perspective. Modern Women, 3, 31-32.

Zhao, Z. (2010). Pragmatic Analysis in Pride and Prejudice. Journal of Chinese Education, 12, 26-29.

\section{Copyrights}

Copyright for this article is retained by the author, with first publication rights granted to the journal.

This is an open-access article distributed under the terms and conditions of the Creative Commons Attribution license (http://creativecommons.org/licenses/by/4.0/). 